\title{
Behaviour of first-row transition elements during early differentiation of arc magmas, Solomon Islands, SW Pacific: Implications for the redox state of sub-arc mantle
}

KWAN-NANG PANG ${ }^{1}$, TruONG TAI NGUYEN ${ }^{1}$, SUn-Lin

CHUNG $^{1}$, SHIGENORI MARUYAMA ${ }^{2}$, TSUYOSHI

KOMIYA $^{3}$, YOSHIYUKI IIZUKA ${ }^{1}$, HAO-YANG LEE ${ }^{1}$

${ }^{1}$ Institute of Earth Sciences, Academia Sinica, Taipei, Taiwan

${ }^{2}$ Earth-Life Science Institute, Tokyo Institute of Technology, Tokyo, Japan

${ }^{3}$ Department of Earth Science and Astronomy, The University of Tokyo, Tokyo, Japan

Many first-row transition elements (FRTE) are redoxsensitive, making them ideal candidates in exploring the redox states in magmatic systems. Because arc lavas in general are differentiated, it is challenging to apply proxies involving these elements to investigate the oxygen fugacity of sub-arc mantle. A cogenetic suite of arc magmas, wherein the most primitive members are in direct equilibrium with the mantle, is thus valuable because it gives an opportunity to examine source geochemistry and how elemental systematics changes with differentiation. Here, we document new geochemical analyses for picritic and basaltic lavas from the Solomon arc, SW Pacific with a specific focus placed on FRTE. The lavas have variable $\mathrm{MgO}$ with the picritic ones mostly in $\mathrm{Fe} / \mathrm{Mg}$ exchange equilibrium with Fo89-91 olivine. With $\mathrm{MgO}$ as a proxy for differentiation, $\mathrm{Cr}$, Co and $\mathrm{Ni}$ behave compatibly, and $\mathrm{V}, \mathrm{Cu}$ and $\mathrm{Ga}$ behave incompatibly. Iron and $\mathrm{Zn}$ might have partitioning behaviour intermediate between compatible and incompatible. Scandium gently increases with decreasing $\mathrm{MgO}$ before it plummets at $\sim 8 \mathrm{wt} . \% \mathrm{MgO}$, consistent with the onset of clinopyroxene fractionation. The above trends indicate that the oxybarometric proxies $\mathrm{V} / \mathrm{Sc}, \mathrm{V} / \mathrm{Ga}$ and $\mathrm{Zn} / \mathrm{Fe}$ 的 applied to the picritic and relatively primitive basaltic lavas for oxygen fugacity estimation. The oxygen fugacity of the mantle source from which these lavas derived can be tightly constrained at FMQ to FMQ - 1. Covariation of $\mathrm{MgO}$ and $\mathrm{Cu}$ further indicates that the oxygen fugacity during differentiation did not exceed FMQ +1.3 . Our results concur with the view that the redox state of sub-arc mantle asthenosphere is similar to that of MORB-source mantle, and that high $\mathrm{Fe}^{3+} / \mathrm{Fe}_{\mathrm{T}}$ generally seen in arc lavas and basaltic glasses therein is a result of transcrustal magmatic processes. We speculate that subducted slab-derived fluids, while rich in incompatible trace elements and probably oxidizing, do not have much leverage in resetting the redox state of sub-arc mantle asthenosphere. 